Uşak Üniversitesi Sosyal Bilimler Dergisi

$2015,8 / 1$

\title{
Yeni Medya Etkileşim Ortamlarında Kadın Hareketlerinin Önündeki Toplumsal Engeller
}

Dilek YEŞİLTUNA*

\section{Özet}

Günümüzün Yeni iletişim teknolojileri, toplumlarda önemli bir dinamik alan oluşturmaktadır. Bu teknolojiler üzerinden toplumlar, sosyal, siyasal, kültürel, vb. alanlarda küreselleşebilmekte, böylece çeşitli coğrafyaların ilişkileri küresel alana taşınabilmektedir. Bu sürecin ortaya çıkardığı sonuçlar üzerinden duyarlılık kazanmış kadın hareketleri, yeni medya olanakları içinde küresel dünyaya eklemlenebilmektedir. Böylece, çeşitli coğrafyaların kadın hareketleri, yeni medya ortamında, küresel dünyanın hareketleri ile ilişkilerini geliştirebilmekte, hareketlerin yerel dinamikleri temelinde farklılıklar ve ara sentezler oluşabilmektedir. Çünkü kadınlara sunulan medya olanakları ile kadınların bu olanaklardan yararlanma düzeyleri üzerinde, halen yerel toplumsal dinamiklerin etkili olduğu görülmektedir.

Kadınların çeşitli medya ortamlarında temsil edilmesi, erkek egemen dünyanın ve çeşitli sektörlerin talepleri yönünde biçimlenmektedir. Diğer yandan, sosyal koşullar bütün dünyada kadınların yeni iletişim teknolojilerini kullanma pratiklerini etkilemekte ve onları erkeklerin gerisinde bırakmaktadır. Gerçekte birçok toplumsal sorunlarının çözümünde destek bekleyen ya da çözümsüzlükler içinde yönsüzleşen kadınların, yeni medya olanaklarına sahip olma düzeyleri de düşük olmaktadır. Bununla birlikte, yeni medyanın eski medyadan farklı olanakları, örgütlenme biçimleri ve çeşitli aktörlere hareket serbestliği sağlaması, yeni medyayı toplumsal sorunların tartışılabildiği, geleneksel medyadan farklı olarak, yeni karşıt kamusallıkların içerilebildiği bir mecra yapmaktadir.

Yeni medyanın olanakları herkesi eşit ve özgür kılıyor görünse de, özellikle kadınların önünde farklı sosyal engellerin olduğu görülmektedir. Küresel dünyanın postmodern kültürünün oluşturduğu bireyselleşme, kadınlığa uygun görülen girişimler, sorunların çözümü ile ilgili duyarlılığ zayıflatmakta, sistemin kadına yüklediği yanlış bilincin de etkisi ile kadınlar, kamusal alandan uzak tutulabilmektedir. Çünkü, postmodern kültür

* Doç. Dr., Ege Üniversitesi Edebiyat Fakültesi Sosyoloji Bölümü 
kadınları hem bireyselleştirerek yalnızlaştırmakta hem de onları tüketime yönelterek temel gereksinimleri bulanıklaştırmakta, aralarındaki dayanışmaları kırabilmekte, kadın duyarılılı̆ının gelişimini yavaşlatabilmektedir. Gerek gelişmiş dünyanın gerekse gelişmekte olan dünyanın bu alandaki sorunları birçok yönden birbiriyle kesişebilmektedir.

$\mathrm{Bu}$ çalışmada kadın hareketleri, gelişmiş ve gelişmekte olan dünyadaki eski ve yeni medya olanaklarını kullanım ve örgütlenme pratiklerindeki cinsiyet farklılıkları ve kadın sorunları bağlamında, kuramsal olarak tartışılmaktadır.

Anahtar Kelimeler: Yeni Medya, Toplumsal Cinsiyet, Kadın Hareketleri, Sosyal Engeller, Tüketim Kültürü.

\title{
The Social Barriers against Women's Social Movements in the New Media Interaction Environments
}

\begin{abstract}
The new media technologies have constituted an important dynamic field in today's societies. Societies can globalize through these technologies in social, political, cultural and other areas, thereby the relationships between various regions can be reflected in the global space. Women's movements gaining sensitivity as a result of this process can be articulated with the global world through new media opportunities. Thus, women's movements in various geographies can develop relationships with the global world's movements in the new media environment and differences and syntheses can be formed on the basis of the local dynamics because it seems that local social dynamics still affect the media opportunities offered to women and the level at which women can benefit from these opportunities.

The representation of women in various media environments has been shaped according to the male dominated world and the demands of various industries. On the other hand, social conditions have influenced women's practical use of new media technologies all over the world and have left women behind men. In fact, women who are waiting for support or who are helpless in terms of finding solutions to their various social problems have new media opportunities at low levels. Besides, the new opportunities of the new media different from the old media, the organizational structures in the new media and the new media's enabling various actors to act freely have led the new media to be an area in which social problems can be discussed and an area that includes new opposite public spheres, which differentiate the new media from the traditional media.
\end{abstract}


Although it seems that the possibilities of the new media make everyone equal and free, there are different social barriers against especially women. Individualization, which is created by postmodern culture in the global world, and actions regarded as suitable for women have weakened the sensitivity related to the solution to the problems and women can be kept away from the public spheres as a result of the influence of the false consciousness that the system imposes on women because postmodern culture makes women individualized and isolated, blurs their basic requirements by directing women towards consumption, it can break the solidarity between them and slow down the development of female sensitivity. The problems of both the developed and the developing world can intersect with each other in these areas in terms of various aspects.

In this study, women's movements are discussed theoretically in the context of the use of old and new media opportunities in the developed and developing world and gender differences and women's problems in organizational practice.

Key Words: New Media, Gender, Women's Movements, Social Barriers, Consumer Culture.

\section{Giriş}

Günümüz küresel dünyası, önemli teknolojik değişimleri ve gelişimleri içerdiği gibi, yerel ve küresel düzeyde ekonomik, sosyal, kültürel, politik, hukuksal vb. açıdan yeni kurumsallaşmalar ve eğilimleri ortaya çıkarmıştır. Böylesi bir süreçte, bireylerin kendilerine ve çevrelerine ilişkin algıları da, dönüşen değişen koşullara bağlı olarak oluşmaya başlamıştır. İnsanların tüm pratiklerini etkileyen ve onu mikro eyleminde makro düşünmesi yönünde zorlayıcı olan kilit faktör, küreselleşme kavramında ifadesini bulan sosyal olgu olmaktadır.

Zaman - mekan kenetlenmesini içeren bir dünyada yerel kalmak, toplumsal sefaletin ve geriliğin bir göstergesi olmaktadır. Küreselleşme, kamusal mekanları yerelleşmiş yaşamın kapsamı dışına çıkartmakta, yerel birimler anlam yaratma ya da anlam müzakere etme kapasitelerini kaybetmekte ve giderek denetimleri dişındaki anlam verme ve yorumlama eylemlerine bağımlı hale getirmektedir (Bauman, 1999, s.9). Böylesine genişleyen ve karmaşıklaşan bağımlılık ilişkileri insanların korku ve kaygılarını da değiştirmektedir. İnsanların bildiği ve öngördüğü koşullara ilişkin korkuların yerini giderek tam olarak kavrayamadığı olası durumlardan kaynaklanan kaygılar almaktadır. Somut bir neden olmadığ 1 zaman bile insanın endişe içinde olmasına işaret edecek şekilde Sennett, bu 
tür kaygıya "yüzergezer" kaygı demektedir. En yoğun olarak da kendini rakip ile iş arkadaşlığ 1 arasındaki çizginin belirsizleştiği çalışma yaşamında göstermektedir (Sennet, 2009 43, 122)

İnsanların böylesine anlam dünyalarını, algılarını ve ilişkilerini değiştiren koşullar, belli bir tarihsel döneme tekabül etmektedir. Harvey, 1970'li ve 80'li yılları bir ekonomik yeniden yapılanmanın ve toplumsal ve politik bir uyarlanma sürecinin yaşandığ 1 sıkıntılı bir dönem olarak tanımlamaktadır. Ona göre söz konusu dönem, tümüyle yepyeni bir birikim rejimine ve onunla bağlantılı olarak bütünüyle farklı bir politik ve toplumsal düzenlemeye geçiş sürecinde ilk kıpırtıların olduğu bir dönem olmaktadır. Yeni koşullar, emek süreçleri, işgücü piyasaları, ürün ve tüketim kalıpları bakımından esnekliğe dayanmaktadır. Ayrıca bu dönem, yepyeni üretim sektörlerinin, finans hizmetlerinde yepyeni yöntemlerin, yeni piyasaların ortaya çıkması ve daha da önemlisi ticari, teknolojik ve örgütsel yeniliklerin temposunun artması anlamına gelmektedir. Diğer yandan, esnekliğin ve akışkanlığın artışından gelen güç, sermayeye, işgücü üzerinde daha güçlü bir denetin uygulama olanağı sunmaktadır. Böylece, sendikal geleneği içeren, örgütlü işçi hareketinin altındaki zemin, sermayenin sahip olduğu hareket kabiliyetiyle, kaydırılabilir olmaktadır (Harvey, 1999, 170-171).

Hipermodern olarak da nitelenebilen yeni toplumsal koşullarda, toplumsal sinıflar dağılmakta, bireyler toplumsal olarak var olmak için giderek yalnızlaştıkları bir mücadele ile karşı karşıya kalmaktadır. Bu koşullarda hiper modern birey işini, mekanını ve yaşam tarzını değiştirmeye hazır olmak zorundadır. Özerkliği, inisiyatifi, etkililiği, sorumluluğu, iletişimi ve hareketliliği ön plana alan çalışma yaşamında, sosyo-ekonomik değişimlere sürekli uyum sağlayabilme yeteneği bir norm haline gelmektedir. Bu bağlamda, toplumsal hareketler de değişmekte ve sınıf mücadelesi kavramı bulanıklaşmaktadır. Bugün herkesten mesleki kariyerini yönetir gibi "yaşamını yönetmesi" istenmekle birlikte, bu yönetim eşitlikçi bir yönetim olmamaktadır (Gaulejac, 2013, 208,211).

Böylece yeni küreselleşen koşullar herkesi, kendi kendisinin yöneticisi kılmakta, bunun başarabilmek için sürekli geliştirmek zorunda olunan bilgi ve beceri kaynaklarını elde etmede, onları rekabet ve yarış ilişkilerine dahil etmektedir. Karmaşık bir bağlantılılığa (Tomlinson, 2004,12) dayanan sosyal ve ekonomik işleyişte bireyler eşit olanaklara sahip olamadığı gibi, karşılaşabileceği sıkıntı ve zorlukları, kendi öz yönetiminin başarısızlığı olarak görmek zorunda bırakılmaktadır.

Yerel ve küresel arasında yaşanan karşılıklı ve karmaşık etkinlikleri içeren bağlantılar, yalnızca ekonomik alanda değil, aynı zamanda toplumsal akışları, insanların enformasyonunun, şirketlerin, fikirlerin ve imajların 
akışını da kapsayan (Urry, 1995,209) geniş bir alanda gerçekleşmektedir. Bu ekonomik ve kültürel tüm alanlarda karmaşık dönüşümleri getiren bağlantıları örgütleyici temel ilke, kapitalizmi artık gerçekten küresel bir güç haline getiren ilke olmaktadır. Küreselleşme mantığına göre esnekleşen şirketler artık, dünyada kalite, verimlilik, ürün çeşitliliği ve piyasa bilgisine dayanarak işlemek ve rekabet etmek zorunda kalmaktadır. Küresel şirketlerin rekabeti, giderek zamana bağlı hale gelirken yenilik yaratımı kadar, dağıtım ve tüketim sürelerini de hızlandırmaktadır. Bunun yanında süreç, merkezsiz ve çok merkezli şirketlerin doğmasını da getirmektedir. Böylesi zaman-mekan sıkışması içeren küresel üretim ve pazarlama, gelişmiş bir varlık-erişebilirlik gerekliliği de yeni bilgisayar sistemleri ve elektronik ağlar yoluyla, yeni bir bilgi akış uzamına dayanmaktadır (Morley, Robins, 1997, 152-155).

Çeşitli ve farklı düzlemlerde yayılan, esnekleşme, ilişkileri düzenleyen ağlar, emek karşısında güçlenen sermaye, çalışma ilişkilerinin bireyselleşmesi ve çeşitlenmesi, aynı zamanda giderek evrensel, sayısal bir dili konuşan yeni bir iletişim sistemi, hem kültürel üretimi ve dağıtımı küresel olarak uyumlu hale hem de onları bireysel beğenilere uygun hale getirmektedir. Süreç aynı zamanda, teknolojik devrim olarak da nitelenebilen gelişmelerin getirdiği bilgi ve enformasyonu, bilgi üretimine, bilgi işleme/iletme aygıtlarına uygulanmasını ve yenilik ile yeniliğin kullanımı arasında karşılıklı bir bağlılık getirmektedir (Castells, 2005, 1-40).

Bu bağlamda insanların ortaya çıkan algılarını oluşturan sorunlar çeşitlenip farklılaşabildiği gibi, sorunlara yönelik rahatsızlıklarını, tepkilerini ortaya koyma biçimleri de değişmektedir. Öncenin makro sınıfsal toplumsal hareketleri yerini mikro alanların temsiliyetini de içeren toplumsal hareketlere bırakmıştır. Bu nedenle, günümüzde ortaya çıan toplumsal hareketler ve bu hareketlerde yer alan insanların konumları, gelişen bilişimiletişim ve ulaşım teknolojilerinin olanaklarına dayandığı kadar, değişen ekonomik, sosyal koşulların niteliğine de bağlı olmaktadır. Bu çerçevede, yeni toplumsal hareketler çerçevesinde kadın hareketlerinde kadının konumu, çalışmamızda, söz konusu iki boyut temelinde ele alınacaktır.

\section{Yeni Medya ve Kadın}

Günümüz toplumunu ve bireylerini tanımlayan en önemli özelliklerden biri, bireyler ve toplumlar arasında çok yönlü iletişim ve bağlılıklar kurabilmelerini sağlayacak teknolojik olanaklara sahip olmasıdır. $\mathrm{Bu}$ olanaklar, bireysel ve toplumsal boyutta gerçekleşen tüm pratikleri etkilemesi ya da tüm pratiklerde yeni koşulların kendini dayatması nedeniyle çok önemli bir faktör olmaktadır. İnsanların gündelik 
yaşamlarında yeni olanaklar yeni fırsatlar anlamına gelirken o aynı zamanda, yeni sorular ve eşitsiz alanları anlamına da gelmektedir.

Bu çerçevede içinde yer aldığımız dünya, giderek enformasyon ve iletişim teknolojileriyle doyurulan bir dünya olurken, aynı zamanda toplumsal cinsiyet, ırk, etnisite, engellilik konumları temelinde tabakalaşmış, ayrıcalıkların ve dezavantajların olduğu bir dünya olmaktadır (Gill, 2007,7). $\mathrm{Bu}$, aynı zamanda yeni medya olarak ifade edebileceğimiz gelişmiş bilişim iletişim teknolojisinin getirdiği dijital ortamın nasıl tanımlandığına bağlı olarak değişmektedir. Nitekim Jenkins bu konuda iki paradigmadan söz etmektedir (2006, 2-7): Yakınsaklık paradigması ve dijital devrim paradigması. Burada yakınsaklık çoklu medya platformlarındaki içerik akışına ve çoklu medya endüstrileri ile medya izleyicilerinin edinecekleri deneyimlere dayalı göç davranışı arasındaki ilişkiye işaret etmektedir. Bu anlamda yakınsallık paradigması eski ve yeni medyanın çok kompleks biçimlerde etkileşime gireceğini kabul etmektedir. Dijital devrim paradigması ise yeni medyanın eski medyayı yerinden edeceğini ve her şeyi değiştirmeye başladığını iddia etmektedir.

Günümüzde teknolojik ortamıla ilgili böylesi gündeme gelen paradigmaların hangisinin geçerli olduğunu tespit etmek için, yeni medyanın işleyiş sisteminin içerdiği özelliklere bakmak gerekmektedir. Bunun için yeni medyanın eski medyadan ya da geleneksel medyadan ayrılan özellikleri, onun işleyiş yapısının temelini oluşturmaktadır. Onlar genellikle, dijitallik, etkileşimsellik, çoklu medya biçemselliği, hipermetinsellik, kullanıcı türevli içerik üretim, yayılım ve sanallık/ara yüzeyde mevcudiyet duygusu olarak siralanabilmektedir (Binark v.d. 2013, 19). Monovich ise onları sayısallık, modülerlik, otomasyon, değişkenlik ve dönüştürme ilkeleri şeklinde başlıklandırmaktadır (Monovich, 2004, 27-45). Daha da önemlisi çok çeşitli toplumsal kesimler tarafından yeni medya endüstrisi klas, yaratıcı ve eşitlikçi olarak kabul edilmektedir (Gill, 2002, 1). Yeni teknolojilerin sağladığı hızlılık ve yaratıcılık günümüzde özellikle ekonomik işleyişin içerdiği kuralları ve gereklilikleri hızla değiştirmektedir. Günümüzde para kazanmak için sadece ürün ve hizmetlerde değil, süreçlerde, iş ve yönetim modelinde yenilikçilik, yaratıcılık ön plana çımış ve rekabet edebilmenin ön şartı haline gelmiştir (Özmen, 2013, 10). Aslında böylesi gereklilikler sadece ekonomik alanda değil, her alanda bireysel, kurumsal ve ulusal bazda temsil edilmenin gereklilikleri olarak ortaya çıkmaktadır. Tüm bunlara karşın, ilgili kaynaklara ulaşma ve kullanma becerisi noktası, insanlar arasındaki eşitsizliklerin somutlaştığı bir alanı oluşturmaktadır. Çünkü günümüz neo liberal piyasa koşullarında insanların rekabet etme ya da var olma gücüne ulaşabilmenin yolu, sürekli yenilenen 
teknolojik gelişmelerin gerektirdiği bilgi ve becerilere sahip olmaktan geçmektedir. $\mathrm{O}$ da, nitelikli bir eğitim sürecinden geçmeyi ve bunun için de uygun ekonomik sosyal koşullara sahip olmayı gerektirmektedir.

2012 Dünya Kalkınma Raporu, hem yüksek hem de düşük gelirli ülkelerde, eğitimdeki toplumsal cinsiyet farklılıklarının, erkekler ve kadınlar arasındaki verimlilik ve ücret farklılıklarını önemli ölçüde etkilendiğini ortaya koymaktadır. Nitekim çalışmalar, kadınlar ve erkekler arasında, teknoloji kullanımı ve erişimi konusunda önemli bir farklılık olduğunu göstermektedir. Örneğin birçok gelişmekte olan ülkede kadınlar internet kullanıcılarının küçük bir kısmını temsil etmektedir. 2000 yılında bu oranlar Etiyopya'da \%16, Venezuala'da \%31 ve Hindistan'da \%27 olarak saptanmaktadır (Warner v.d., 2013, 9).

Türkiye'de de Türkiye İstatistik Kurumu verilerine (TUIK) göre kadınların bilgisayar ve internet kullanımı, erkeklerle karşılaştırıldığında, çok açık bir farklılık gözlenmektedir (TUIK, 2004-2013). 16-74 yaş grubundaki bireylerde 2004'te erkeklerde bilgisayar ve internet kullanımı \% 31,7 ve $\% 25,7$ olurken, kadınlarda bu oranlar $\% 16$ ve $\% 12,1$ şeklinde ortaya çıkmaktadır. Sırasıyla aynı oranlar 2013 yılı verilerinde erkeklerde \% 60.2 ve $\% 59,3$ olurken kadınlarda \% 39,8 ve \% 38,7 olmaktadır. Görüleceği üzere kadınlar ve erkekler arasında bilgisayar ve internet kullanımı dokuz yılda göreli bir artış göstermekle birlikte, kullanım düzeyleri arasındaki farklılığın daralması beklenebilecekken, daha da aralık açılmaktadır.

Morley'in televizyon üzerine yaptığı, evde medya kullanımının, aile ve toplumsal cinsiyet normları gibi ögelerce inşa edilen sosyal ilişkilerle bağlantılı olduğu noktasından hareket eden Werner'in İsveç'te 2005-2006 yıllarını kapsayan sekiz ayda, 14-16 yaşlarındaki kızların gündelik yaşamda müzik kullanımını içeren çalışması da, evdeki yaş ve cinsiyet temelli toplumsal cinsiyet inşasının yeni medya teknolojilerinin kullanımında etkili olduğunu ortaya koymaktadır (Werner, 2009, 269-284). Bu konudaki bulguları birkaç noktada özetlemek mümkündür.

Onlar;

- Kızların çoğunluğu her gün birkaç saat bilgisayardan ve mp3 çalardan müzik dinlemektedir.

- Okul arkadaşı olan kızlar arasında MSN'de online olmak yaygındır ve o çeşitli paylaşımlar için pratik bir sosyal araç olmaktadır.

- Toplumsal sinıf ve etnik farklılıklar, evde müziğe ve dijital medyaya erişimlerini doğrudan etkilememekle birlikte, erişimin niteliği ve niceliği, ebeveynlerin gelir ve çalışma tipine bağlı olarak farklılaşmaktadır.

- Evde büyük erkek kardeşi olan kızların tümünde ve küçük erkek kardeşleri bulunan bazılarında da, kızların medya teknolojilerine ulaşımı, 
ebeveynlerinde onayıyla, sınırlanmaktadır. Aile bu konuda önceliği erkek kardeşe vermektedir.

- Evde sadece kız kardeşlerin olması durumunda ise, kızların medya teknolojisiyle erişimleri sınırlanmamakla birlikte teknoloji öncelikle ortak alanda yer almakta, ailenin gelir düzeyi artması durumunda kız odasında özel teknolojiye sahip olabilmektedir.

- Ayrıca kızlar, erkek kardeşlerinin ve ebeveynlerinin erkeklerin bilgisayar kullanımında daha becerikli olduğu düşüncesini paylaşmakta ve evde adil olma konusunda ki sosyal düzenle ilgilenmemektedirler.

Türkiye'de Intel tarafından 2009 yılında 16 yaş üzerinde kişilerin katıldığ 1 "Bilgisayar Kullanımı ve Tutum Araştırılması"nın sonuçları da, kadınların bilgisayara ve internete erişim ve kullanımında dezavantajlı konumda olduklarını ortaya koymaktadır (Intel, 2009). Araştırma, hanelerin $\% 48,4^{\prime}$ ünde ailenin yetişkin oğlu, \%4,6'sında babanın, \%30,3'ünde ailenin yetişkin kızının ve yalnızca \% 18'inde annenin bilgisayar kullandığını göstermektedir.

Sonuçta araştırmalarda da ortaya konduğu gibi medya pratikleri, aynı zamanda toplumsal cinsiyet, sosyal güç pratikleri ve evdeki kimlik yapılarıyla kesişmektedir (Werner, 2009,281). Bu nedenle, kızların özlemlerini, özerkliklerini ve geleceklerini planlama ve öngörme kapasitelerine katkıda bulunan tüm karar verme yeteneklerini geliştirebilen bir kalitede eğitimi edinme olanakları (Warner, 2013,10) kilit bir öneme sahip olmaktadır.

Diğer yandan kadınların yeni medya ile ilişkilerindeki toplumsal cinsiyet temelli konumlarının üretilmesinde ve meşrulaştırılmasında, bu sektörde çalışan profesyonel kadınların konumları da önemli rol oynamaktadır. Nitekim Avusturya, Finlandiya, İrlanda, Hollanda, İspanya ve İngiltere olmak üzere altı Avrupa ülkesini içeren bir çalışma klas, yaratıcı ve eşitlikçi olarak görünen yeni medya endüstrisinin toplumsal cinsiyet temelli eşitsizliğini, nasıl yeniden ürettiğini ve aynı zamanda eşitlikçi bir maske taktığını ortaya koymaktadır (Gill, 2002, 1-26). Söz konusu çalışma 125 serbest yeni medya çalışanıyla, farklı araştırma teknikleri kullanılarak gerçekleştirilmiştir. 25-35 yaş aralığında olup, 2-6 yıldır yeni medya sektöründe çalışan örneklem grubunda kadınlar, erkeklere göre işe yeni girenleri oluşturmaktadır. Onların \%93'ü üniversite mezunu, yarısı (lisansüstü eğitimli, çoğu üniversite sonrası programlama, dijital düzenleme v.b. konuda ek eğitim almıştır. Katılımcıların çoğu, işlerin rollerden çok daha önemli olduğunu, örgütsel bir hiyerarşi olmaksızın onu bir takım çalışması olarak tanımlamaktadırlar. Buna bağlı olarak da çalışmanın en cazip yanının rollerin akışkanlığı olduğunu ifade etmektedirler. Bunun 
yanında, toplumsal cinsiyet grupları arasında önemli farklılıklar bulunmaktadır. Onlar arasında projeler dengesiz dağıtılmaktadır. Yapılan işten, erkekler yılda 16.000 Euro kazanırken, kadınlar 10.000 Euro kazanmaktadır. Kadınlar daha fazla kazanmak için daha fazla zaman harcamaktadır. Yeni iş fırsatlarına ulaşım, informal olarak kontrol edilmektedir ve bu süreçte her zaman kişiler arası bağlantılar tahsis edilmektedir. Bu bazı kadınlar için "eski erkek ağı" faaliyeti olarak algilanmakta ve cinsiyetçi bir dışlanma biçimi olarak görülmektedir. Kadınlar bu koşullarda çoğunlukla zorunlu olarak evden çalışırken, erkekler büro v.b. kiralamaktadırlar. Çocuk sahibi olanlar grup içinde çok az yer alırken, onlar da erkeklerden oluşmaktadır. Kadınlar çocuk sahibi olmayı seçmiyorlardı. Çalışma yeni medya sektöründeki kadın ve erkeklerin kariyerleri arasında açı farklılıklar olduğunu göstermektedir.

\section{Yeni Toplumsal Hareketler ve Kadın}

Günümüzde giderek yaygınlaşan elektronik kampanyalar, gruplar, toplumlardaki her türlü farklılıkların her geçen gün temsiliyetinin artmasının bir ifadesi olmaktadır. Buradan hareketle daha demokratik, eşitlikçi ve özgür bir toplumun ortaya çıkıp çıkmadığı önemli bir tartışma konusu haline gelmektedir. Daha öncede belirttiğimiz gibi, günümüz sosyal olaylarının ya da hareketlerinin temelinde iki dinamik bulunmaktadır. İlki, insanlar arasındaki ilişki ve etkileşimi arttıran teknolojik gelişmeler, ikincisi de insanların yaşama dair algılarını değiştiren, dönüştüren, sosyal, ekonomik, politik koşullar olmaktadır.

Touraine $(1999,47-50)$ toplumsal yaşamı, kendi kendini üreten ve dönüştüren bir hareket olması temelinde onu, tarihselliğin üretildiği, çatışmaların gerçekleştirildiği, öznenin bilincinin temellendirildiği bir sistem olarak tanımlamaktadır. Bir toplumsal hareket de kendisi aracılığıyla kültürel yönelimlerin tarihsellik alanının bir toplumsal örgütlenme biçimine dönüştüren bir çatışma davranışı olmaktadır.

Günümüz sosyal hareketlerinin Offe $(1999,63-67)$ önceki ya da eski sosyal hareketlerden farklı kılan özelliklerin belli temalarda ele alınarak analiz edilebileceğini ileri sürmektedir. Bunlar hareketlerin sorunsallaştırdıkları temalar, değerler, hareket biçimleri ve aktörler olmaktadır. Bu bağlamda, sosyal hareketlerin içerdiği paradigmaları "eski" ve "yeni" politik paradigma ayrımı yaparak, özelliklerini dört temada açıklamaktadır. Bunlar, aktörler açısından, eski grup olarak hareket eden, gelir dağılımı çatışmasına müdahil sosyo-ekonomik gruplar, yeni hareket de grup gibi davranmayan fakat belli temalar etrafında bir araya gelmiş topluluklar lehine hareket eden sosyo-ekonomik gruplar olmakta; temalar 
açısından eski hareketler ekonomik büyüme ve dağıtım, askeri ve toplumsal güvenlik, toplumsal kontrolü içerirken, yeni hareketler, barış, çevrenin ve insan haklarının korunmasını içermektedir; değerler açısından, özgürlük, tüketim güvenliği ve maddi ilerleme, yeni hareketlerde, merkezi kontrolün karşısında kişisel özerklik ve kimlik şeklinde ortaya çıkmakta; hareket biçimleri açısından ise eski, resmi örgütlenmeler, büyük ölçekli temsil birliklerinden oluşan içsel ve çoğulcu ya da korporatist çıkar aracılığı, siyasal parti rekabeti ve çoğunluk oyundan oluşan dişsal hareket biçimlerinin yerini, yeni hareketlerde, enformalite, düşük düzeyde dikey ve yatay farklılaşmadan oluşan içsel ve negatif terimlerle formüle edilmiş taleplere dayanan protesto politikalarından oluşan dişsal hareketler almıştır.

Böylesi özellikler taşıyan sosyal hareketlerin en önemli özelliği olarak Martin (2008, 295-303) devlet iktidarını ele geçirmeye yönelmemesi ve hatta siyasi bir partiyle bağlantı kurmanın bile yöntem olarak terk edilmesini işaret etmektedir. Bu nedenle, günümüz hareketlerinin birikim ve sömürü süreçlerinin kontrolünü elinde tutan siyasal iktidar üzerinde hakimiyet kurmaksızın, özgürlüğe nasıl ulaşılacağı sorunsalının içerdiği ikilem üzerinden işlediğine dikkat çekmektedir. Bu özellik de, günümüzdün doğrudan eylemlerinde giderek artan anarşizmde ifadesini bulmaktadır. Sonuçta, Martin, söz konusu ikilemin, yeni sosyal hareketlerin içerdiği yöntemin başarıya ulaşacağ öngörüsüne sahiptir.

Küreselleşen neoliberalizmin içerdiği temel özellikler rekabet, güvensizlik, esneklik, kuralsızlık, rasyonalite, yaratıcılık ve hız olmaktadır. İnsanların yaşamlarının her hücresine sirayet eden bu özellikler, onları özyönetimlerinden sorumlu tutan ve bu bağlamda bireyselleştiren bir sistemi hakim kılmaktadır. Böylece bireyleri, yaşamın içerdiği potansiyel her türlü sorun ve risk karşısında yalnız bırakmakla birlikte, bireyleri çözüm sürecinin her aşamasında birey olarak konumlanmak zorunda bırakmaktadır.

Böylesi koşullarda bireylerin varoluşlarını zorlaştıran en önemli faktör de, kendi zamanlarına tutumlarının üzerinde gerçekleşeceği zeminin kaygan olmasıdır. Bu da belirsizliğin siyasal ekonomisinin bir ürünü olarak ortaya çıkmaktadır. Bu süreçte, iktidar giderek küreselleşirken, bütün yerleşik siyasal kurumlar mekana bağlı kalmaktadır. Böylece, iktidarın denetimi giderek güçleşmekte, adeta imkansız hale gelmektedir. Bu aşamada en büyük tehlike, insanların kendi yaşamlarını denetleme konusunda güçsüz oldukları sonucuna gitmeleri ve kabul etmeleridir. Çünkü bu yönelim kendi özerkliklerini kaybetmelerinden hareketle, toplumun özerkliğini kaybetmesi demektir. Bu nedenle özerk bir yurttaş 
olmak için eş zamanlı olarak "makro" ve "mikro" düzeylerde çaba sarf etmek gerekmektedir (Bauman, 2001, 68-74).

Tam da bu noktada, yani insanların özerk bir birey olma ve böylece kendi yaşamlarının denetimini ele geçirebilmelerinin tek yolunun farklı düzlemleri bir araya getirebilen bir mücadele içine girmek zorunda olmaları, hem bireysel hem küresel pratiklere aracilık eden, bilişim - iletişim teknolojilerinin önemini ve sahip olabileceği kilit rolü ortaya koymaktadır. Çünkü yeni medya olarak tanımlanabilen teknolojilerin sahip olduğu özellikler, insanların sosyal mücadelelerini oluşturma, geliştirme ve sonuca ulaştırma konusunda, insanlara önemli olanaklar sunmaktadır.

Nitekim Bennett'in (2003, 25-26) günümüz küresel eylemlerini oluşturan üç önemli bağlantı olarak sıraladığı noktalar, yeni toplumsal hareketler ile yeni medya arasındaki ilişkiyi özetler niteliktedir. Onlar, kimliği modern örgütlerin düzenleyici ilkelerinden bağımsızlaşması, zaman - mekan ve mesafelerinin yeniden düzenlenmesi ve bu iki faktörün birleşiminden kaynaklanan daha sofistike ve iç bağlantılı iletişim ağlarının kurulmasıdır. Bu anlamda ortaya çıkan küresel iletişimin alt yapısı, geleneksel iletişimden farklı özellikler taşımaktadır. Onlar, sıradan insan tarafından yüksek nitelikli içerik üretilmesini, bu içeriğin büyük oranda interaktif ağlarla yaratılmasını, üretilen içeriğin sınırlar ve kıtalar arasında geçişinin artması ve kişisel içeriğin kitle medya içeriğine girişinin daha etkinleşmesiyle, medya sistemlerinin yakınlaşmasıdır.

Gerek sosyal koşullar, gerekse ona paralel gelişen teknolojik olanaklar, ortaya çıan sosyal hareketlere farklı özellikler kazandırıp, eski ve yeni olarak kategorize edilse de, onlar üç temel ögede kesişmektedir. Bir sosyal hareket, dayanışmaya dayalı bir çatışma taşıyan ve yer aldığı sistemin sınırlarını zorlayan bir kolektif hareket biçimi (Melucci, 1999, 87) olmasıyla tarihsel bir boyuta sahip olması bağlamında, diğerlerinden ayrılmaktadır.

Sonuçta, çevrecilik, etnisite, cinsel kimlik ve barış gibi temalar etrafında örgütlenen grupların toplumsal sahnenin yeni aktörleri olarak, toplumsal hareketler yeni özellikler kazanmıştır. Bu çerçevede, kadın hareketi de kadını geleneksel bağlarından özgürleştirmek ve toplumsal alanlara erkeklerle eşit düzeyde katılmalarını içeren bir söylemden, eşitliğin ötesinde farklılık ve ötekilik hakkını da talep eden söyleme doğru evrilmiştir.

Böylece günümüz kadın hareketleri, ekonomik ve sınıfsal temelli bir hareketten kültürel, kimlik temelli bir harekete doğru dönüşürken, önceki söyleminden vazgeçmekten çok, onu da içeren bir kapsamda farklılıklarıyla var olma hakkını talep eden bir hareket olmaktadır. 


\section{Sonuç Yerine}

Her toplum, her kültür belli bir iletişim yapısı içermektedir. Söz konusu iletişim sürecinin içerdiği üretim, paylaşım ve tüketim mekanizmalarının işleme biçimi, verili kültürün üyelerinin hak ve yükümlülüklerini de biçimlendirmektedir. Bu çerçevede toplumsal cinsiyet temelinde ortaya çıkan kadın-erkek eşitsizliği kendini iletişim sürecinin içerdiği her aşamada üretmektedir. Bu anlamda, sosyal bir gerçek ile onun temsili arasında doğrudan bir ilişki bulunmaktadır.

Gill'in altı Avrupa ülkesinde yeni medya sektöründe çalışanlarla çalışma, kadınlarla erkekler arasında gerek işe giriş ve çalışma koşulları gerekse aldığı ücret konusunda, net olarak saplanabilen, fakat açıkça görülemez kılınmış bir eşitsizliği ortaya koymaktadır. Aynı ülkelerde kadın ve erkeğin işgücüne katılım düzeylerine baktığımızda ise ilk oran erkek işgücü olmak üzere veriler şu şekilde ortaya çıkmaktadır: $(67,7-54,6),(66,5-$ 52,6), (64,3-56), (61,8-50,9) (68,8-56,7), (67,9-52,7), (70,9-58,7). Görüleceği üzere işgücüne katılan kadın ve erkek arasında ortalama \%10'luk bir farklılık bulunmaktadır. (TUIK, 2012)

Bu ülkelerin dışında yer alan Türkiye'ye baktığımızda ise işgücüne katılan erkek oranı \%71 olurken kadın oranı \%29,5 olmaktadır. Böylece, burada kadın-erkek işgücüne katılım farklılığı \%41,5 olmaktadır. Buradan hareketle ortalama \%10'luk bir farklılığın getirdiği eşitsizliği dikkate aldığımızda ülkemizdeki \%41,5'lik farklılığın ne denli şiddetli bir eşitsizliği içerdiği ortaya çıkmaktadır.

Sonuçta kadınların bireysel, özerkliklerine yönelik kimlik mücadelesi, onların içine yer aldıkları aile yapısından ve sosyal-kültürel çevresinden bağımsız olmamaktadır. Bu nedenle, yeni medyanın kadınlara özgürlük, özerklik, eşitlik gibi olanaklar sunmasının temelinde sürekli gelişen ve karmaşıklaşan yeni medya teknolojisine sahip olmalarına ve onları etkin şekilde kullanılabilme becerileri kazanmalarına dayanmaktadır. Mevcut toplumsal cinsiyet anlayışının içerdiği dinamikleri dikkate aldığımızda, kadın hareketinin diğer toplumsal hareketlere göre daha zayıf ve yavaş seyredeceğini söyleyebiliriz.

\section{Kaynakça}

BAUMAN, Z., 1999, Küreselleşme- Toplumsal Sonuçları, Ayrıntı Yay., İstanbul.

BAUMAN, Z., 2001, Bireyselleşmiş Toplum, Ayrıntı Yay., İstanbul.

BENNETT, W. L., 2003, "New Media Power : The Internet and Global Activisim", Ed: Nick Couldry, James Curran, Contesting Media 
Power: Alternative Media in a Networked World, Rowman-Littfield Publishers, Inc. USA, (17-36).

BINARK, M., Bayraktutan, G., 2013, Ayın Karanlık Yüzü: Yeni Medyada Etik, Kalkedon Yay., İstanbul.

CASTELLS, M., 2005, A $\breve{g}$ Toplumunun Yükselişi- Enformasyon Çağı: Ekonomi, Toplum ve Kültür (I. Cilt), İstanbul Bilgi Üniversitesi Yay., İstanbul.

GAULEJAC, V., 2013, İşletme Hastalığına Tutulmuş Toplum, Ayrıntı Yay., İstanbul.

GILL, R., 2002, "Cool, Creative and Egalitorian? : exploring gender in project based new media work in Europe, London: LSE. Research Online, http://eprints.lse.ac.uk/2446 (03.05.2014).

GILL, R., 2007, Gender and Media, Polity Press, Cambridge.

HARVEY, D., 1999, Postmodernin Durumu, Metis Yay., İstanbul.

INTEL, 2009, Bilgisayar Kullanım ve Tutum Araştırması, http://download.potkal.com/dosyalar/Intel_Rapor_LRes.pdf (15.05.2014).

JENKINS, H., 2006, Covergence Culture: Where Old and New Media Collide, New York University, New York.

MANOVICH, L., 2002, The Language of New Media, The MIT Press, Cambridge.

MARTIN, W., 2008, “Sonuç: Dünya Hareket Dalgaları ve Dünya Dönüşümleri", Ed: W. G. Martin, Toplumsal Hareketler 1750-2005, Versus Kitap, İstanbul.

MORLEY, D., Robins, K., 1997, Kimlik Mekanları, Ayrıntı Yay., İstanbul.

OFFE, C., 1999, "Yeni Sosyal Hareketler : Kurumsal Politikanın Sınırlarının Zorlanması", Ed: Kenan Çayır, Yeni Sosyal Hareketler, Kaktüs Yay., İstanbul

ÖZMEN, Ş., 2013, Ağ Ekonomisinde Yeni Ticaret Yolu- E-Ticaret, İstanbul Bilgi Üniversitesi Yay., İstanbul

SENNETT, R., 2009, Yeni Kapitalizm Kültürü, Ayrıntı Yay., İstanbul.

TOMLINSON, J., 2004, Küreselleşme ve Kültür, Ayrıntı Yay., İstanbul.

TOURINE, A., 1999, “ Toplumdan Toplumsal Hareketlere”, Ed: Kenan Çayır, Yeni Sosyal Hareketler, Kaktüs Yay., İstanbul.

TUIK, 2004-2013, Bilgi Toplumu İstatistikleri, http://www.tuik.gov.tr/ (15.05.2014).

TUIK-2012,

http://tuikapp.tuik.gov.tr/secilmisUluslararasiGostergeler/tabloolust ur.do, (20.05.2014).

URRY, J., 1995, Mekanları Tüketmek, Ayrıntı Yay., İstanbul. 
WARNER, A., Malhotra, A., Gonagle, A., 2013, Girl's Education, Empowerment and Transitions to Adulthood, The Case for Shared Agenda, International Center for Research on Woman, http://macfound.org/media/files/ICRW) , (03.05.2014).

WERNER, A., 2009, "Girls consuming music at home : Gender and the Exchange of music through new media", Europian Journal of Cultural Studies, 12(3):296-284, DOI: 10.1177/1367549409105364, http://sagepublications.com, (02.05.2014). 